\title{
The Effects of Two Training Programs Regarding Reading Development among Children with Reading Disabilities
}

\author{
Linda Fälth ${ }^{1, *}$, Idor Svensson ${ }^{1}$, Tomas Tjus ${ }^{2}$ \\ ${ }^{1}$ Department of Pedagogic, Psychology and Sports Management, Linnaeus University, Växjö, Sweden; \\ ${ }^{2}$ Department of Psychology, University of Gothenburg, Gothenburg, Sweden. \\ Email: Linda.falth@lnu.se \\ Received December 10 $0^{\text {th }}, 2010$; revised February $9^{\text {th }}, 2011$; accepted April $1^{\text {st }}, 2011$.
}

\begin{abstract}
Aim: The purpose of the study was to examine the effects of two different training programs regarding reading skills in 14 reading disabled Swedish children in grade two. Method: The children's results from two different decoding measures plus identification by teachers as having reading difficulties were used to select the participants. Seven of the children used Omega-IS, which entails computerized top-down, orthographic training and no additional homework, and seven children used non-computerized Reading Recovery inspired training with some components of phonological training included plus 20 homework occasions. For both programs the training sessions were conducted individually (one-to-one teaching) and lasted between 15 and 45 minutes. Results: Both groups improved significantly in all tests assessing word and non-word decoding as a result of the intervention. No significant differences were yielded between the intervention programs. Conclusion: The conclusion is that one-to-one teaching has a positive impact regardless whether a top-down or a reading instructional strategy with phonological components is implemented. Due to the result of the Omega-IS group it might also be possible to reduce homework for reading disabled children if reading is well tutored in school.
\end{abstract}

Keywords: Children, Intervention, Reading and Writing Disabilities

\section{Introduction}

Since there has been an increasing demand for literacy skills in modern society, a failure in this domain can seriously affect an individual's possibility to be an active citizen in democratic respects. Approximately 15 to 20 percent of school children in Sweden have some kind of reading and writing disabilities (Lundberg, 1985). Constant failure and the feeling of not being able to read are devastating for the self-esteem and may increase the risk of drop-outs in school, which in turn might enhance the risk of being marginalized in society (McNulty, 2003; Svensson, 2010). The negative effects of reading and writing disabilities and dyslexia involving low self-esteem seem to be most profound during the first 6 years of schooling (Stanovich, 1986). Findings also indicate that the early identification of literacy difficulties as well as the intervention process can even prevent reading disabled children from developing negative self-esteem (Humphrey, 2002; McNulty, 2003). It is therefore important to not only early identify, but also to remediate the children who are likely to encounter literacy difficulties in the future.

There is an abundance of research papers that have focused on reading and writing disabilities, but less than $1 \%$ of these studies have concerned intervening with dyslexia (Bakker, 2006). However, there are a number of studies attempting to examine individual differences in response to specific intervention, some of the methods used being computerized and some not. For example, an intervention study which did not use computerized programs was made by Torgesen et al. (2001) of 60 children between the ages of 8 and 10 with the focus on reading and writing. Half of the children were randomly assigned to a training program called ADD (Auditory Discrimi- nation in Depth), which focuses on children's phonological skills through auditory and articulatory exercises. The other half used a program called EP (Embedded Phonic), which also focuses on children's phonological awareness, but through different types of texts, spelling exercises and strategies. All children received a total of 67.5 hours of one-to-one teaching, each divided into two 50-minute sessions per day for 8 weeks. Results showed that both groups made significant progress on tests that measure reading ability, and the results proved to be stable two years after the intervention. One year after the intervention ended it was reported that $40 \%$ of the participants were not in need of special education any longer. Another example is a computerized longitudinal intervention study of reading disabled children in grades 2-3, which showed that phonological and orthographic word decoding skills need to be taken into account when suggesting interventions (Gustafson, Ferreira \& Rönnberg, 2007). This study also demonstrated that children with pronounced phonological word decoding problems showed more progress in reading after phonological than after orthographic training, while children with pronounced orthographic problems benefited more from orthographic than from phonological training.

Longitudinal intervention studies in different countries have demonstrated that phonological awareness training improves phonological and reading skills in novice readers, at-risk and reading disabled children (Alexander \& Slinger-Constant, 2004; Ball \& Blachman, 1988; Elbro \& Petersen, 2004; Lundberg, Frost \& Petersen, 1988; Poskiparta, Niemi \& Vauras, 1999; Schneider, Kuspert, Roth, Vise \& Marx, 1997; Torgesen, Morgan \& Davis, 1992). The transfer effects from improved phonological skills to improved reading skills seem to be enhanced when the instruction provides explicit links between phonemes 
and graphemes (Bradley \& Bryant, 1983; Bus \& van IJzendoorn, 1999; Ehri et al., 2001; Hatcher, Hulme \& Ellis, 1994; Torgesen et al., 2001; Wise, Ring \& Olson, 1999). The focus of the present study is on early intervention (grade 2) with different kinds of reading and writing difficulties. However, just one of the training programs in the study reported here explicitly contains phonological awareness training, being inspired by Reading Recovery (Clay, 1993) and not computerized. The other, computerized, method, Omega-IS (Omega-Interactive Sentences), is targeted at the word and sentence levels of written language, i.e., top-down processing (Heimann, Lundälv, Tjus \& Nelson, 2004). The present study comparing a computerized method without any homework with a non-computerized method including homework where parents are requested to help the child has child has as far as we know very few reports before.

\section{Aim}

The aim of this study is to examine the effects of two different training programs on the reading skills of reading disabled children. In addition to group comparisons, individual differences of the effects of the interventions will be reported.

Hypothesis. Omega-IS had not been used previously in the clinical setting where the study was conducted, and on the basis of the first author's clinical experience of using Reading Recovery plus the additional homework training provided it was hypothesized that Reading Recovery would outperform the Omega-IS multimedia program in all three outcome measures.

\section{Method}

\section{Participants}

For participation in the study two inclusion criteria were used: (i) Results from two different measures, Fonolek [Phonoplay] and Vad sa du fröken? [What did the teacher say?], made in pre-school with children aged 6 were used in combination. Fonolek (Olofsson \& Hemmingsson, 1993) is a phonological test, which includes sound synthesis, sound segmentation, and a section in which the child is to identify the initial sound, with 18 as the maximum score. A score under 12 is considered to be an indication of phonological problems. Vad sa du fröken? (Alstam-Malcus, \& Fritzell, 2006) is a screening material for pre-school and first graders that map out the beginner's language and speech level. A speech pathologist ranks the speech development at five levels from $\mathrm{A}$ to $\mathrm{E}$, with levels from $\mathrm{A}$ to $\mathrm{C}$ indicating speech problems. The children had to have both a score below 12 on Fonolek and to be ranked from level A, B or $\mathrm{C}$ on Vad sa du fröken? to fulfil the first criterion. Secondly, when the children were in grades 1-4 (in Sweden children usually begin grade 1 at the age of seven) they had to be identified by their teachers as having serious difficulty acquiring wordlevel reading skills. Out of 93 children, 20 (21.5\%) fulfilled the inclusion criterion, and 14 children, all Swedish native speakers, gained the consent of their parents to participate in the study (see Table 1). All participants were assessed by Raven's Coloured Progressive Matrices (Raven, Court \& Raven, 1984), and all scored above the 25 th percentile, i.e. they were within the normal range. They were matched in age, non-verbal cognitive ability, measured by Raven's Coloured Progressive Matrices (Raven et al., 1984), and in decoding skills, assessed by the Wordchains test (Jacobson, 1993); see Measures for a description.

The experimental groups were randomly assigned to using either Omega-IS or Reading Recovery.

\section{Procedure}

The design of the intervention comprised Pre-, Start, Post 1 and Post 2 tests with four weeks between Pre- and Start Tests, six weeks between Start and Post 1 and four weeks between Post 1 and Post 2 tests, creating a baseline, an intervention and a follow-up period (Table 2). Two reading and one non-word reading tests were carried out for all children at Pre, Start, Post 1 and Post 2.

During the baseline period all participants received special tutoring twice a week in the Swedish language, with 3-4 participants in each group. They had no access to any other special tutoring during the time of the intervention study. The group of children who used the Omega-IS multimedia program completed 20 training sessions in total. The sessions lasted from 15 minutes at the beginning to 40 minutes at the end of intervention. No other special tutoring during the intervention was provided, and the children had no reading homework. In the Reading Recovery (RR) group the children received 20 training sessions of 30 - 40 minutes each. This group also had homework linked to the method on 20 different occasions. The homework lasted for 10 - 20 minutes, always with a parent present. All tutoring in the study, both with regard to Reading Recovery and Omega-IS, was made on a one-to-one basis, and the first author (L.F.) carried out all training sessions and assessment in both training programs.

\section{Measures}

Three tests were used in order to measure the participants' reading skills with regard to word decoding.

Word recognition. Word recognition was assessed by the Wordchains test (Jacobson, 1993). The participant is asked to silently read chains of words where the blank space between

Table 1.

Distribution of participants according to grade and gender.

\begin{tabular}{ccc}
\hline \multirow{2}{*}{ Grade } & \multicolumn{2}{c}{ Gender } \\
\cline { 2 - 3 } & Boys & Girls \\
\hline First & 4 & - \\
Second & 2 & 1 \\
Third & 2 & 1 \\
Fourth & 3 & 1 \\
\hline
\end{tabular}

Table 2.

Design of the intervention showing test points and number of weeks for baseline, training and follow-up periods.

\begin{tabular}{|c|c|c|c|c|c|}
\hline Pretest & $\begin{array}{l}\text { Baseline } \\
4 \text { weeks }\end{array}$ & Start test & $\begin{array}{l}\text { Intervention } \\
6 \text { weeks }\end{array}$ & $\begin{array}{l}\text { Post } \\
\text { test } 1\end{array}$ & $\begin{array}{l}\text { Folow-up } \\
4 \text { weeks }\end{array}$ \\
\hline
\end{tabular}


words has been removed. Each chain consists of three semantically unrelated words, and the child is instructed to mark each word boundary with a pencil (Jacobson, 1993).

Sight word reading. This is an individual reading pace test called H4 (Franzén, 1999). In one minute the child should read as many words as possible from a list with commonly used words. The length of the words constantly increases.

Non-word reading. The child has to read from a list as many nonwords as possible in one minute. The words do not exist in reality, but they can be pronounced. Reading nonwords is thought to be done mainly via phonological processing. Since the words are nonwords it can be assumed that the child has never seen the words before; therefore, the orthographic direct way cannot be used (Jacobson, Svensson \& af Trampe, unpublished data).

\section{Training Programs}

\section{Omega-IS}

Omega-IS is a multimedia program that uses a top-down strategy, i.e. by clicking on buttons with words or phrases sentences are constructed. Immediate feedback is obtained for both words and sentences in the form of speech and animations providing corresponding one-to-one semantic comprehension, thus inviting the child to explore written text. The lessons included in the program went from two-(noun + verb) and three-word sentences (noun + verb + noun) up to stories within which the child could construct their own stories and choose different actors and scenarios. This was done in order to increase the children's motivation to explore literacy. Positive results on reading have been reported, for instance for children with autism, cerebral palsy or developmental dyslexia (Tjus, 1998). The language material of the program is meant to be explored by the learner with help from and in interaction with a teacher or parent. This and the appended animations not only offer motivational literacy training but also give occasion for conversations where the learner can express his or her imagination and thoughts. The goal is to achieve an errorless co-con- struction of meaning from text through multimedia and suppor- tive interaction.

\section{Reading Recovery}

An intervention inspired by Reading Recovery (RR) (Clay, 1993) was used in the study. RR was used in a research and development study at Auckland University in the late 1970s and the early 1980s. RR is an educational program that offers early, intensive and individual reading education for children that are slow reading starters. The purpose of the program is, according to Clay (1993), to prevent early reading disabilities from becoming permanent.

The individual educational program cons ists of the following steps:

- Reading two or more well-known, easily read booklets or books

- Reading the booklet or book from the previous day

- Working with words and loose letters

- Writing one or two sentences

- Dissembling the sentences, which includes working with phonemes and word segments

- Reassembling the sentences to their original stage

- Introducing a new booklet or book

All the steps should be dealt with for about 30 - 40 minutes, which makes the tempo pretty high. The teacher takes minutes, a so-called "Running Record" when the child reads the book from the previous day. Reading that book has been the homework together with reassembling the original sentences and reading them out correctly to a parent. The homework takes about 10 - 20 minutes a day. This method offers practice on word and sentence levels but also focuses on phonological awareness (Clay, 1993; Frost, 2002; Jörgensen, 2001).

\section{Statistical Analysis}

The analysis focuses on changes over time in observed means between baseline, intervention and follow-up. The means for each period are calculated as change scores (mean at the end of a period minus mean at the start of the period). Both group comparisons (unpaired t-tests) and within-group comparisons (paired t-tests) are conducted. Even if a hypothesis was stated, a two-tailed significant level (alpha 0.5) was used for conservative reasons, due to the small sample observed. Since non-parametric and parametric methods yielded the same results, only parametric methods are reported.

\section{Result}

The descriptive results are shown both in tables (baseline, intervention, and follow-up periods) and as graphs at Pre-test, Start test, Post 1 and Post 2 tests.

Between-group comparison.

When comparing the Omega-IS group and the RR group for baseline, intervention and follow-up periods on change scores no significant difference was observed for any of the outcome measures (Tables 3 and 4).

Table 3.

Means and standard deviation of raw scores at observation points and change scores during baseline (BL), training (TR) and follow-up (FU) periods for the Omega-IS group.

\begin{tabular}{|c|c|c|c|c|c|c|c|}
\hline & $\begin{array}{c}\text { Pre test } \\
\text { Raw score }\end{array}$ & $\begin{array}{c}\text { Start test } \\
\text { Raw score }\end{array}$ & $\begin{array}{l}\text { Post test } 1 \\
\text { Raw score }\end{array}$ & $\begin{array}{l}\text { Post test } 2 \\
\text { Raw score }\end{array}$ & $\begin{array}{c}B L \\
\text { Change score }\end{array}$ & $\begin{array}{c}\text { TR } \\
\text { Change score }\end{array}$ & $\begin{array}{c}F U \\
\text { Change score }\end{array}$ \\
\hline Word recognition & $\begin{array}{l}15.0 \\
(8.8)\end{array}$ & $\begin{array}{l}15.1 \\
(8.7)\end{array}$ & $\begin{array}{l}21.1 \\
(9.2)\end{array}$ & $\begin{array}{l}21.0 \\
(8.9)\end{array}$ & $\begin{array}{c}0.1 \\
(1.1)\end{array}$ & $\begin{array}{c}6.0 \\
(3.8)\end{array}$ & $\begin{array}{l}-0.1 \\
(0.7)\end{array}$ \\
\hline Sight word reading & $\begin{array}{c}45.3 \\
(30.8)\end{array}$ & $\begin{array}{c}45.0 \\
(30.7)\end{array}$ & $\begin{array}{c}54.3 \\
(31.2)\end{array}$ & $\begin{array}{c}53.6 \\
(30.2)\end{array}$ & $\begin{array}{l}-0.3 \\
(0.9)\end{array}$ & $\begin{array}{c}9.3 \\
(4.8)\end{array}$ & $\begin{array}{c}6.9 \\
(4.8)\end{array}$ \\
\hline Non-word decoding & $\begin{array}{l}18.1 \\
(9.4)\end{array}$ & $\begin{array}{l}17.1 \\
(8.1)\end{array}$ & $\begin{array}{l}21.6 \\
(9.7)\end{array}$ & $\begin{array}{l}20.4 \\
(8.6)\end{array}$ & $\begin{array}{l}-1.0 \\
(1.9)\end{array}$ & $\begin{array}{c}4.4 \\
(2.1)\end{array}$ & $\begin{array}{l}-1.1 \\
(1.3)\end{array}$ \\
\hline
\end{tabular}


Table 4 .

Means and standard deviation of raw scores at observation points and change scores during baseline (BL), training (TR) and follow-up (FU) periods for the Reading Recovery group.

\begin{tabular}{|c|c|c|c|c|c|c|c|}
\hline & $\begin{array}{c}\text { Pre test } \\
\text { Raw score }\end{array}$ & $\begin{array}{c}\text { Start test } \\
\text { Raw score }\end{array}$ & $\begin{array}{l}\text { Post test } 1 \\
\text { Raw score }\end{array}$ & $\begin{array}{l}\text { Post test } 2 \\
\text { Raw score }\end{array}$ & $\begin{array}{c}B L \\
\text { Change score }\end{array}$ & $\begin{array}{c}T R \\
\text { Change score }\end{array}$ & $\begin{array}{c}\text { FU } \\
\text { Change score }\end{array}$ \\
\hline Word recognition & $\begin{array}{c}14.1 \\
(11.0)\end{array}$ & $\begin{array}{c}14.1 \\
(10.3)\end{array}$ & $\begin{array}{c}19.7 \\
(11.8)\end{array}$ & $\begin{array}{c}19.0 \\
(11.3)\end{array}$ & $-0.6(1.6)$ & $\begin{array}{c}5.6 \\
(4.5)\end{array}$ & $\begin{array}{l}-0.7 \\
(1.6)\end{array}$ \\
\hline Sight word reading & $\begin{array}{c}37.9 \\
(23.7)\end{array}$ & $\begin{array}{c}36.9 \\
(21.4)\end{array}$ & $\begin{array}{c}43.7 \\
(23.1)\end{array}$ & $\begin{array}{c}43.4 \\
(22.6)\end{array}$ & $-1.0(3.0)$ & $\begin{array}{c}6.9 \\
(4.8)\end{array}$ & $\begin{array}{l}-0.3 \\
(0.9)\end{array}$ \\
\hline Non-word decoding & $\begin{array}{l}12.1 \\
(5.0)\end{array}$ & $\begin{array}{l}11.9 \\
(4.6)\end{array}$ & $\begin{array}{l}16.0 \\
(5.1)\end{array}$ & $\begin{array}{l}15.4 \\
(5.4)\end{array}$ & $-0.3(0.9)$ & $\begin{array}{c}4.1 \\
(2.9)\end{array}$ & $\begin{array}{l}-0.6 \\
(0.8)\end{array}$ \\
\hline
\end{tabular}

The groups were matched on the word recognition test and the mean for the groups on the Pre 1 test was identical $(\mathrm{M}=$ 14.71 Wordchains) (see Figure 1). During the intervention (from Start to Post 1) the results on word recognition increased for the Omega-IS group, $\mathrm{M}=6.0, \mathrm{SD}=11.8$ and on average 5.6 wordchains, $\mathrm{SD}=9.2$ for the RR group. The test at Post 2 showed that both groups almost maintained their results, i.e. that the Omega-IS group and the RR group decreased on average by $0.7(\mathrm{SD}=11.3)$ and $0.14(\mathrm{SD}=8.9)$, respectively.

The results for sight word reading show that the Omega-IS group had a better starting point, which means that the children in this group read on average almost 8 more words/minute in comparison with the RR-group when taking the Start test. At Post 1 the Omega-IS group had on average increased by 9.0 words/minute $(\mathrm{SD}=31.2)$ and the increase for the RR-group was 6.3 words/minute $(\mathrm{SD}=23.1)$.

The development curves for nonword decoding showed that the Omega-IS group had on average 5.28 more correctly read nonwords at Start compared to the RR-group (Figure 2). The intervention showed almost the same development in both groups. The Omega-IS group showed an increase by 3.9 nonwords/minute and the RR-group by 4.0 nonwords/minute. At Post 2 the results showed a decrease for the Omega-IS group by

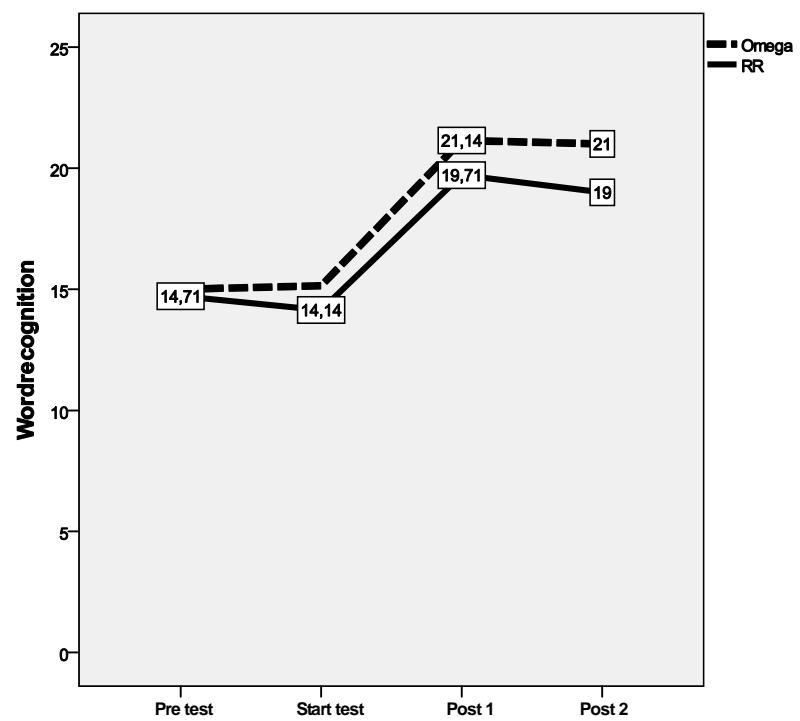

Figure 1.

Development curves for word recognition.
1.1 nonwords, and a decrease for the RR-group by 0.6 nonwords.

\section{Within-Group Comparison}

\section{Omega-IS}

In the comparison of the different periods, a significant increase appeared when comparing change scores on baseline with training for all outcome measures (Table 3 ): Word recognition, $\mathrm{t}(6)=-3.5, \mathrm{p}=0.013$; Sight word reading, $\mathrm{t}(6)=-5.3, \mathrm{p}$ $=0.002$; Non-word decoding, $\mathrm{t}(6)=-4.2, \mathrm{p}=0.006$. A significant decrease on all measures was yielded when comparing training with follow-up period: Word recognition, $\mathrm{t}(6)=3.9, \mathrm{p}$ $=0.008$; Sight word reading, $\mathrm{t}(6)=5.1, \mathrm{p}=0.002$; Non-word decoding, $\mathrm{t}(6)=4.7, \mathrm{p}=0.003$. No significant differences on any of the measures came out when comparing baseline and follow-up periods.

\section{Reading Recovery}

A significant increase was observed when comparing change scores on baseline with training for all outcome measures (Table 4): Word recognition, $\mathrm{t}(6)=-2.9, \mathrm{p}=0.028$; Sight word reading, $\mathrm{t}(6)=-3.9, \mathrm{p}=0.008$; Non-word decoding, $\mathrm{t}(6)=-3.7$,

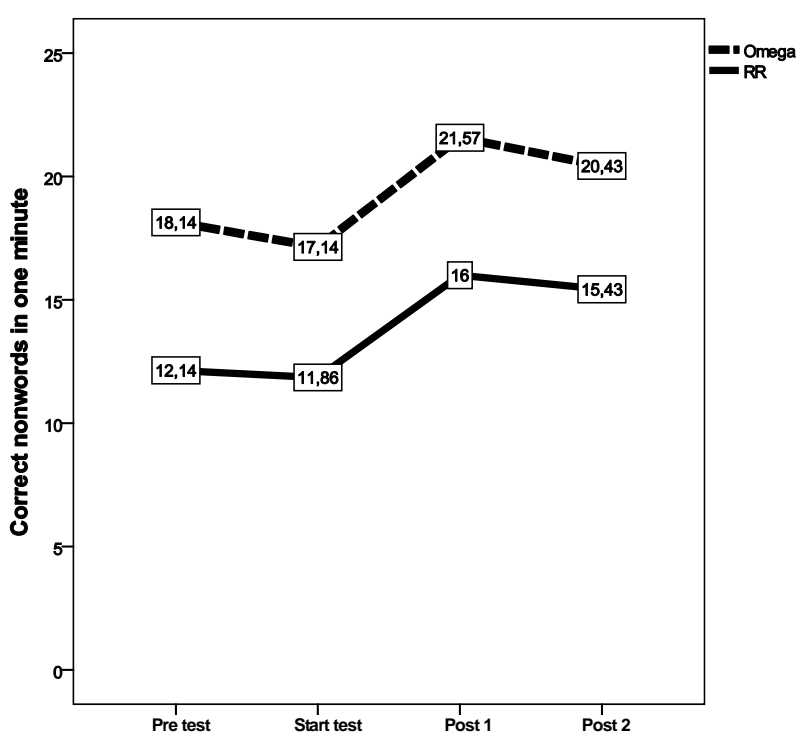

Figure 2.

Development curves for Phonological decoding test. 
$p=0.010$. A significant decrease was yielded on all measures when comparing training with follow-up periods: Word recognition, $\mathrm{t}(6)=3.2, \mathrm{p}=0.019$; Sight word reading, $\mathrm{t}(6)=3.9, \mathrm{p}=$ 0.008 ; Non-word decoding, $\mathrm{t}(6)=5.1, \mathrm{p}=0.002$. When comparing baseline and follow-up periods no significant differences were noted on any of the measures.

\section{Individual Results}

Figures 3 and 4 show individual curves for the word recognition test wordchains and the test that measures phonological decoding, i.e. nonword decoding.

The individual curves follow almost the same pattern regardless of the starting level at which the child started, i.e. there is an obvious increase between Start test and Post test 1, except for a couple of children where there is almost no development at all.

The individual curves follow almost the same pattern for the phonological decoding test as for the word recognition test. Regardless of the level at which the child started, there is an obvious increase between Post 1 and Post 2, except for a couple of children where there is hardly any development at all.

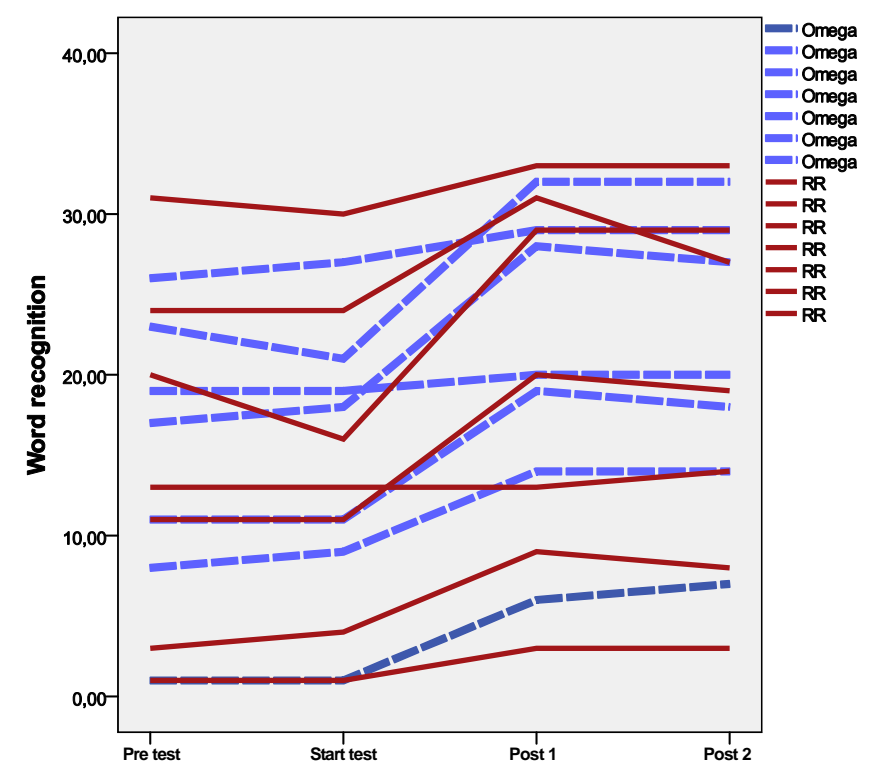

Figure 3.

Individual curves for word recognition test.

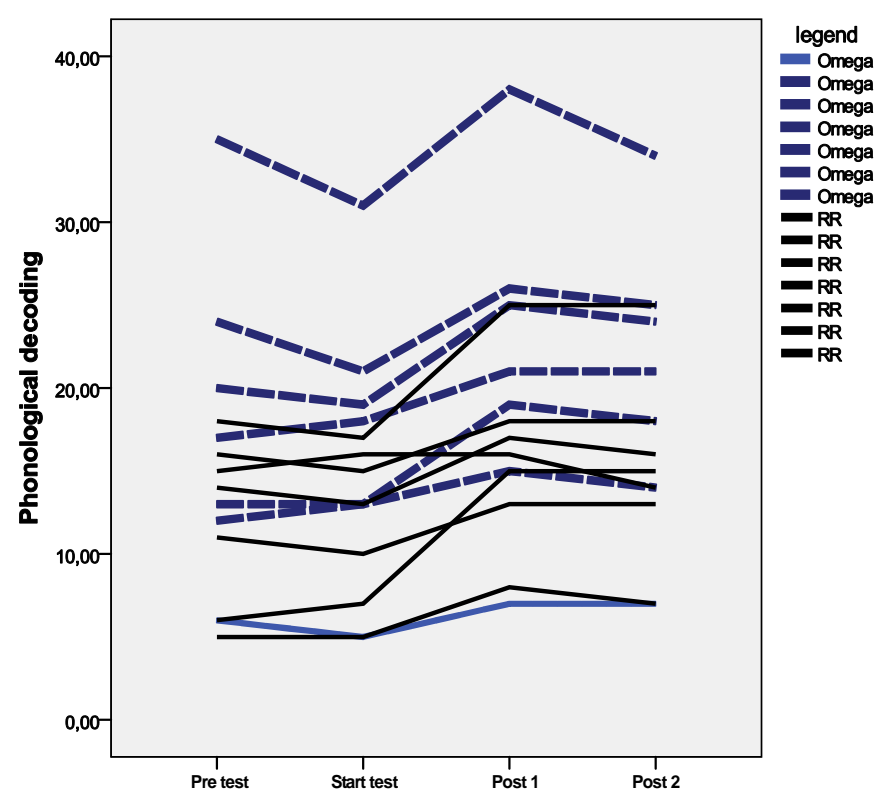

Figure 4.

Individual curves for Phonological decoding. 


\section{Discussion}

The aim of the present study was to measure the effects of two intervention programs with the purpose of improving reading ability. The most striking finding from this study was the size of the gains in reading achievement made by this sample of disabled readers. At the group level both groups increase significantly between the Start and Post 1 tests and then the result curve flattens out between Post 1 and Post 2. As we expected, when the intervention is completed, there is no development on the varied skills tested, but the results remain even at the Post 2 test.

There are several different instructional methods when it comes to learning and improving reading ability, two of which are used in this study. The results showed that both groups, regardless of the method used, improved during the intervention in all of the tests measuring word recognition and phonological ability compared to baseline. However, there was no significant difference between the groups, even though the children in the Reading Recovery group had additional homework. It was hypothesized that Reading Recovery would outperform the Omega-IS multimedia program in all three outcome measures. This was not evidenced; instead the results indicate that a computer-based training program may be as effective as a non-computerized program for practising reading.

Looking at the results at the individual level, we see that some children have benefited greatly from the intervention, while others have hardly made any progress in, for example, their word decoding skills. One interpretation might be that some children respond positively to the type of intervention they received and that it was the right training for these particular individuals. Other children who did not respond positively to the intervention might have gained more if they had been exposed to the other intervention program or to some other type of intervention.

Even if this was not examined it can be speculated that those children who showed progress also increased their motivation for reading and enjoyed their training method. We have showed (Tjus, Heimann \& Nelson, 2001) that enjoyment increases in children with learning disabilities as an effect of reading intervention and an important domain of children's self-concept is reading and writing skills having an impact on their self-perceived competence (Harter, 2006). Mc Nulty (2003) has shown that early remediation is important for the academic self esteem. However, the children showing no increase in reading gain may in contrast become frustrated and tired of the training they received. With the design used it was not possible to change training method. The ideal would have been to use a cross-over design letting the children use both methods but this was not possible due to human resources.

The study shows that intense one-to-one teaching, regardless of the method used, may increase children's reading ability. This could indicate that it is the teacher that matters providing pedagogical and emotional support, that it is indeed the effect of the teacher which makes a difference. However, in this study the same teacher who worked with the children in the ordinary special education taking place before the interventions also performed all interventions with all children. Test results show that there is no development between the Pre-test and the Start test, and the fact that the intervention does have an effect seems to indicate that it is the interventions that are crucial for the results of the Post 2 tests. During the interventions only oneto-one teaching was used, which was not the case during the regular special education taking place before the interventions. Children with this type of difficulty seem to take advantage of one-to-one teaching and it might be that the interaction between child and teacher increases exposure also to spoken language, which is crucial for long-term language development (Hart \& Riesly, 1995).

Although the groups were initially matched on word recognition, they differ in particular at baseline in the test that measures non-word decoding, despite the fact that the two groups increase equally on this test. The children in the Omega-IS group generally reached the same results, even though they did not have homework. This is an interesting result since homework is looked upon as tiring by both children and parents. Many of the participants in this study say that they often feel that their homework takes too much time and effort. The results of this study actually show that with the right kind of training it might be able to achieve the same results on reading skills without a great deal of homework. A limitation of this study is the small number of participants and that the children are attending different grades. This makes it difficult to interpret the results according to a specific age.

The experience of children working with the multi-media program in this study is that both the technologies in themselves and the fact that the computer program gives continuous feedback on children's reading make a good incentive. A multi-media program that is stimulating for the children can give the same increase of reading ability and be a compliment to the original reading education, as has been shown in previous studies (Tjus 1998; Tjus, Heimann \& Nelson, 2004).

The reading process is a very complex cognitive activity involving many sub-processes and systems. It is therefore not surprising that a group of reading disabled children tend to be quite heterogeneous, exhibiting different types of reading problems and also different challenges for remediation. Therefore, it is important that teachers have access to several different approaches and methods when remediating children with reading and writing disabilities. The result from the current study indicates that both of the intervention programs showed promising results. However, the results should be interpreted with caution, due to the small number of participants, and also taking into consideration that there was no control group in this study. It is hard to speculate about what the results would have been if these children had been part of the regular teaching and not been included in this study, which gives emphasis to the importance of having a control group to compare the results with. However, the design with a baseline the four-week gap in between the Pre-test and the Start test ensures the starting position, and the fact that virtually no development takes place in these weeks suggests that the effect was due to the intervene- tion. The Post 2 test after 4 weeks also contributes to making the results of the measurements intestable values. Furthermore, average improvements in reading skill might hide substantial individual differences in the effects of the intervention (Gustafson, Samuelsson, \& Rönnberg, 2000; Torgesen \& Davis, 1996). Considering the few intervention studies related to reading instruction, we think that educational interventions should be regarded from a dynamic rather than a static perspective. Recent studies in the fields of dynamic testing and assessment and response to intervention demonstrate the need to think of 
educational interventions as ongoing processes where assessment can assist intervention and vice versa (see Grigorenko, 2009).

There is now strong evidence that the main manifestation of developmental dyslexia is word decoding deficits and that these shortcomings mainly stem from underlying phonological deficits (Bruck, 1992; Lundberg, Olofsson \& Wall, 1980; Rack, Snowling \& Olson, 1992; Stanovich \& Siegel, 1994; Svensson \& Jacobson, 2006). There is also strong evidence of biological (Galaburda et al., 1985; Morgan \& Hynd, 1998) and genetic (Galaburda et al., 2006; Grigorenko, Ngorosho, Jukes \& Bundy, 2006) influences that contribute to phonological deficits and poor word-decoding skills. The results of this study point to the importance of individualizing both testing and intervention, and the need for more systematic and scientific research on how to best adapt interventions to the specific needs of individual children. In a forthcoming investigation, with a sufficient number of participants, we are going to make deeper analyses regarding both orthographic and phonological aspects of different interventions and subgroups of reading disabilities.

\section{References}

Alexander, A. W., \& Slinger-Constant, A.-M. (2004). Current status of treatments for dyslexia: Critical review. Journal of Child Neurology, 19, 744-758.

Alstam-Malcus, A., \& Fritzell, M. (2006). Vad sa du fröken? Umeå: Specialpedagogiska institutet.

Bakker, D. J. (2006). Treatment of development dyslexia: A review. Paediatric Rehabilitation, 9, 3-13.

Ball, E. W., \& Blachman, B. A. (1988). Phoneme segmentation training: Effect on reading readiness. Annals of Dyslexia, 38, 208-225. doi:10.1007/BF02648257

Bradley, L., \& Bryant, P. E. (1983). Categorising sounds and learning to read: A causal connection. Nature, 301, 419-421. doi: $10.1038 / 301419 \mathrm{a} 0$

Bruck, M. (1992). Persistence of dyslexics' phonological awareness deficits. Developmental Psychology, 28, 874-886. doi:10.1037/0012-1649.28.5.874

Clay, M. (1993). Reading recovery: A guidebook for teachers in training. Auckland: Heinemann Education.

Ehri, L. C., Nunes, S. R., Willows, D. M., Valeska Schuster, B., Yaghoub-Zadeh, Z., \& Shanahan, T. (2001). Phonemic awareness instruction helps children learn to read: Evidence from the National Reading Panel's meta-analysis. Reading Research Quarterly, 36, 250-287. doi:10.1598/RRQ.36.3.2

Elbro, C., \& Petersen, D. K. (2004). Long term effects of phoneme awareness and letter sound training: An intervention study with children at risk for dyslexia. Journal of Educational Psychology, 96, 660-670. doi:10.1037/0022-0663.96.4.660

Frost, J. (2002). Läsundervisning - Praktik och teorier. Stockholm: Natur och Kultur.

Galaburda, A. M., Sherman, G. F., Rosen, G. D., Aboitiz, F., \& Geschwind, N. (1985). Developmental dyslexia: Four consecutive cases with cortical anomalies. Annals of Neurology, 18, 222-233. doi:10.1002/ana.410180210

Grigorenko, E. L. (2009). Dynamic assessment and response to intervention: Two sides of one coin. Journal of Learning Disabilities, 42, 111-132. doi:10.1177/0022219408326207

Grigorenko, E., Ngorosho, D., Jukes, M., \& Bundy, D. (2006). Reading in able and disabled readers from around the world: Same or different? An illustration from a study of reading-related processes in a Swahili sample of siblings. Journal of Research in Reading, 29, 104-123. doi:10.1111/j.1467-9817.2006.00295.x

Gustafson, S., Samuelsson, S., \& Rönnberg, J. (2000). Why do some resist phonological intervention? A Swedish longitudinal study of poor readers in grade 4. Scandinavian Journal of Educational Research, 44, 145-162. doi:10.1080/713696666

Gustafson, S., Ferreira, J., \& Rönnberg, J. (2007). DOT: Datorbaserad ortografisk träning. linköping: Institutionen för beteendevetenskap/ Institutet för handikappvetenskap, Linköpings universitet.

Hart, B. \& Riesly, T. R. (1995). Meaningful differences in the everyday experience of young American Children. Baltimore, MD: Brookes.

Harter, S. (2006). The self. In: N. Eisenberg, W. Damon \& R. M. Lerner, Eds., Handbook of Child Psychology, Social, emotional, and personality development, 6th Edition, John Wiley \& Sons Inc, Hoboken, 3, 505-570.

Heimann, M., Lundälv, M., Tjus, T., \& Nelson, K. E. (2004). OmegaIS, a multimedia software for enhancing language and communication development in children with disabilities.

Humphrey, N. (2002). Teacher and pupil ratings of self-esteem in developmental dyslexia. British Journal of Special Education, 29, 29. 36. doi:10.1111/1467-8527.00234

Jacobson, C. (1993). Manual till ordkedjetestet. The Word chains test; Manual. Psykologiförlaget, Stockholm.

Jörgensen, K. (2001). Lyckas med läsning, läs- och skrivinlärning i Nya Zeeland. Stockholm: Bonnier Utbildning AB.

Lundberg, I. (1985). Språk och läsning. Stockholm: Liber.

Lundberg, I., Olofsson, Å., \& Wall, S. (1980). Reading and spelling skills in the first school years predicted from phonemic awareness skills in kindergarten. Scandinavian Journal of Psychology, 21, 159173. doi:10.1111/j.1467-9450.1980.tb00356.x

McNulty, M. A. (2003). Dyslexia and the life course. Journal of Learning Disabilities, 36, 363-381. doi:10.1177/00222194030360040701

Morgan, A. E., \& Hynd, G. W. (1998). Dyslexia, neurolinguistic ability, and anatomical variation of the plenum temporal. Neuropsychological Review, 8, 79-93. doi:10.1023/A:1025609216841

Olofsson, Å., \& Hemmingsson, I. (1993). Fonolek. LPC Östersunds kommun.

Poskiparta, E., Niemi, P., \& Vauras, M. (1999). Who benefits from training in linguistic awareness in the first grade, and what components show training effects? Journal of Learning Disabilities, 32, 437-446, 456.

Psykologiförlaget, A. B. (1995). Raven's Matrices - Coloured. Stockholm: Psykologiförlaget.

Rack, J. P., Snowling, M. J., \& Olson, R. K. (1992). The nonword reading deficit in developmental dyslexia. Reading Research Quarterly, 27, 29-53. doi:10.2307/747832

Raven, C., \& Raven. (1994). Raven's coloured progressive matrices. Psykologiförlaget.

Stanovich, K. E. (1986). Matthew effects in reading: Some consequences of individual differences in the acquisition of literacy. Reading Research Quarterly, 21, 360-407. doi:10.1598/RRQ.21.4.1

Svensson, I., \& Jacobson, C. (2006). How persistent are phonological difficulties? A longitudinal study of reading retarded children. Dyslexia, 12, 3-20. doi:10.1002/dys.296

Taube, K., Tornéus, M., \& Lundberg, I. (1984). UMESOL. Stockholm: Psykologiförlaget.

Tjus, T. (1998). Language and literacy acquisition in children with developmental and learning disabilities. Göteborgs Universitet, Psykologiska institutionen.

Tjus, T., Heimann, M., \& Nelson, K. E. (2004). Interaction patterns between children and their teachers when using a specific multimedia and communication strategy: Observations from children with autism and mixed handicaps. Autism, 5, 175-188.

Tjus, T., Heimann, M. \& Nelson, K. E. (2004). Reading acquisition by implementing a multimedia intervention strategy for fifty children with autism or other learning and communication disabilities. Journal of Cognitive and Behavioural Psychotherapies, 2, 203- 221.

Torgesen, J. K., Alexander, A. W., Wagner, R. K., Rashotte, C. A., Voeller, K. K. S., \& Conway, T. (2001). Intensive remedial instruction for children with severe reading disabilities: Immediate and long-term outcomes from two instructional approaches. Journal of 
Learning Disabilities, 34.

Torgesen, J. K., Morgan, S., \& Davis, C. (1992). Effects of two types of phonological awareness training on word learning in kindergarten children. Journal of Educational Psychology, 84, 364-370. doi:10.1037/0022-0663.84.3.364
Wise, B. W., Ring, J., \& Olson, R. K. (1999). Training phonological awareness with and without explicit attention to articulation. Journal of Experimental Child Psychology, 72, 271-304.

doi:10.1006/jecp.1999.2490 